\title{
ENCONTRO NACIONAL DA ANPAD X MEETING OF AOM: LIÇÕES, QUESTIONAMENTOS E ESPECULAÇÕES
}

RESUMO

Este trabalho compara dois congressos científicos na área de administração e "management", o vigésimo sexto Encontro da Associação Nacional de Programas de Pós-Graduação em Administração (ANPAD) e o Sexagésimo segundo "meeting" da Academy of Management (AOM), ambos realizados no ano de 2002. A partir desta comparação, procuram-se extrair possíveis aprendizados, observandose as tendências futuras que possam permitir avanços a este tipo de evento.

\section{Rogério Hermida Quintella}

UFBA

ABSTRACT This paper is aimed to compare two scientific meetings on management and administration subject, the 26th Meeting of The Brazilian Academy of Management, Business and Administrative Sciences and the 62nd Meeting of The Academy of Management, both realized in 2002. Based upon this comparison some lessons and learning are used in the observation of future trends, which would allow the progress of this kind of event.

PALAVRAS-CHAVE Congresso de administração, encontro de administração, gestão de eventos científicos. KEY WORDS Management meetings, managing scientific meetings 


\section{INTRODUÇÃo}

Este texto tem como objetivo traçar algumas linhas de comparação entre o maior evento acadêmico na área de administração da América do Norte, o Meeting of the Academy of Management, e seu equivalente brasileiro, o Encontro da ANPAD - ambos em 2002. A intenção é a de informar aos pesquisadores da área sobre as peculiaridades de cada evento, dando assim uma noção do que representa o Encontro da ANPAD frente ao maior encontro do gênero no mundo. A partir dessa comparação, são feitas algumas especulações sobre as tendências de eventos científicos desse tipo.

O Enanpad surgiu em 1976, quando os coordenadores de dez programas se encontraram em Nova FriburgoRJ para discutir os rumos da pós-graduação em Administração no Brasil. A partir desse encontro, dois outros foram realizados no mesmo ano para construção e aprovação dos estatutos da ANPAD. De lá para cá, foram 26 encontros anuais.

Os encontros da Academy of Management, por sua vez, surgiram 36 anos antes de seus congêneres brasileiros, transformando-se no principal evento mundial no gênero e, dessa forma, em um benchmarking natural para o Enanpad. Em 2002, a Academy realizou sua 62ª edição.

Diversos estudos já foram publicados sobre os encontros da ANPAD, como, por exemplo, Bertero, Caldas e Wood Jr. (1998), Caldas, Tonnelli e Lacombe (2001), Hoppen et al. (1998), Machado-da-Silva, Carneiro da Cunha e Amboni (1990), Rodrigues Filho (2002), Teixeira Jr. (2002) e Vergara e Souza Carvalho Jr. (1995). Outros discutem os encontros da Academy of Management, como Beatty (2002) e Payne (1988). Nenhum deles, entretanto, compara os eventos com outros de mesma natureza. Tal comparação parece ser extremamente interessante como exercício de "benchmarking de eventos científicos". Este é o objetivo deste texto: comparar os eventos da ANPAD e da Academy of Management (AOM) de forma a permitir a identificação de oportunidades e desafios à evolução dos mesmos.

\section{ANÁLISE QUANTITATIVA DOS EVENTOS}

No que tange ao tamanho dos dois eventos, a conferência da Academy teve um total de 6,4 mil participantes em 2002 contra 850 inscritos no evento da ANPAD. Alguns outros dados refletem essa diferença de escala entre os encontros, por exemplo: enquanto o Enanpad demandou 15 salas simultâneas em 2002, a conferência norte-americana utilizou um total de 120 espaços.
É importante salientar que essas diferenças, de ordem de grandeza, acabam por aí. Em termos de submissão de papers, a escala norte-americana é apenas o dobro daquela do Enanpad, tendo atingido a marca de 4 mil submissões contra 2 mil do evento brasileiro em 2002. Deve-se observar, porém, que a Academy trata apenas de management, enquanto o evento da ANPAD inclui áreas tão grandes e diversas quanto marketing, finanças e outras que não se incluem no conceito de management adotado pela Academy. Esse tema será retomado na próxima seção.

Continuando com as comparações quantitativas, podese dizer que, no que se refere à média de inscritos, há, em ambos os eventos, uma média de aproximadamente 50 congressistas inscritos por sala. Esse aspecto, a distribuição física dos participantes, traz algumas importantes variáveis à tona. Dentre elas, a mais importante é a variedade de formatos de apresentação de trabalhos. Esse importante aspecto será retomado algumas seções à frente.

A comparação quantitativa preliminar pode mostrar, também, alguns indicadores discretamente mais favoráveis ao evento brasileiro, a exemplo da informatização de sistemas e processos e o tratamento estatístico das avaliações.

Um terceiro tipo de características e indicadores poderá ser considerado mais favorável a um evento ou outro, a depender da postura do observador. Um exemplo desse tipo de característica é o índice de rejeição de trabalhos, índice que, de fundamental importância, pode ser visto como mais favorável a um ou a outro encontro, a depender da contextualização da discussão. Enquanto a Academy aceita cerca de $40 \%$ dos trabalhos a ela enviados, no Enanpad esse percentual fica, na média das áreas, próximo a 30\%.

Há de se ter muito cuidado ao fazer tais comparações iniciais, pois o indicador de per si não basta como parâmetro para avaliação de qualidade dos encontros. É certo, na comparação em tela, que o padrão de qualidade dos trabalhos aceitos no encontro da Academy é claramente superior ao dos encontros da ANPAD, sendo lógico supor que o mesmo aconteça com o universo de trabalhos submetidos. Esse tema será novamente discutido na penúltima seção deste texto.

\section{ÁREAS TEMÁTICAS}

A Tabela 1, a seguir, apresenta as 23 áreas da conferência da Academy em 2002 em comparação às 15 áreas temáticas do XXVI Enanpad e seus respectivos percentuais de submissão. 
A Tabela 1 é composta de duas partes. A primeira mostra 11 tracks do evento norte-americano em ordem decrescente em termos do percentual de papers submetidos. Essas 11 são as que encontram correspondência em termos de áreas temáticas no XXVI Encontro da ANPAD. Abaixo das 11 primeiras linhas, a tabela lista, também em ordem decrescente do percentual de papers submetidos, 12 áreas do meeting e três do encontro, as quais não têm equivalentes nos respectivos eventos. $\mathrm{Na}$ coluna da direita, foram listadas inicialmente as 11 áreas do Encontro da ANPAD de 2002 que têm equivalentes na Academy, seguindo-se as demais áreas.

Além do fato de haver uma predominância de áreas comuns aos dois encontros, parece interessante analisar algumas outras peculiaridades que se observam na Tabela 1. A primeira observação a ser feita é a de que, em ambos os encontros, as duas áreas que mais atraem submissão de papers são "Estratégia" e "Comportamento Organizacional". Deve-se, ainda, chamar a atenção para a enorme participação da área de "Estratégia" na Academy, em que esse tema responde por quase um quinto de todas as submissões. Pode-se ver na Tabela 1 que o evento norte-americano é, em essência, um encontro de estudos organizacionais, não havendo, portanto, áreas como marketing, finanças, contabilidade etc.

Observa-se também, que as áreas equivalentes a "Gestão de Ciência e Tecnologia" e "Gestão Internacional" atraem, no encontro da Academy, uma parcela consideravelmente maior de estudiosos do que no Brasil. Por outro lado, no Enanpad, a submissão de trabalhos sobre "Gestão de Pessoas e Relações de Trabalho" e de "Administração da Informação" são proporcionalmente muito maiores. Pode-se especular que tanto a predominância do tema "Estratégia" - no caso norte-americano - quanto a grande participação da área relativa a "Recursos Humanos" - no caso do brasileiro - estejam ligadas a fatores culturais. Já a diferença em termos de percentual de submissões para as áreas de "Gestão Internacional" e "International Management" pode ser facilmente explicada pela maior importância do tema na América do Norte, onde há um enorme número de empresas multinacionais de origem local, fato que não se repete

Tabela 1 - As áreas temáticas da ANPAD X Academy (\% de submissão de papers).

\begin{tabular}{|c|c|c|c|}
\hline TRACK & $\%$ & ÁREA TEMÁTICA & $\%$ \\
\hline Business Policy and Strategy & 17,3 & Estratégia nas Organizações & 9,9 \\
\hline Organizational Behavior & 11,0 & Comportamento Organizacional & 10,1 \\
\hline Organizational and Management Theory & 8,5 & Teoria das Organizações & 6,8 \\
\hline Technology and Innovation Management & 6,8 & Gestão de Ciência e Tecnologia & 4,7 \\
\hline International Management & 6,7 & Gestão Internacional & 3,1 \\
\hline Human Resources & 6,5 & Gestão de Pessoas e Relações de Trabalho & 9,0 \\
\hline Organizational C. and Information Systems & 3,4 & Administração da Informação & 9,6 \\
\hline Management Education \& Development & 2,3 & Ensino e Pesquisa em Administração & 5,1 \\
\hline Research Methods & 2,0 & & \\
\hline Operations Management & 1,6 & Gestão de Operações e Logística & 3,9 \\
\hline \multirow[t]{2}{*}{ Public and Nonprofit Division } & 1,3 & Gestão Pública e Governança & 6,8 \\
\hline & & Políticas Públicas & 4,7 \\
\hline Entrepreneurship & 5,8 & Marketing & 9,2 \\
\hline Social Issues in Management & 3,4 & Contabilidade e Controladoria Gerencial & 8,6 \\
\hline Organization Development and Change & 3,1 & Finanças & 7,4 \\
\hline Management History & 2,9 & Casos de Administração Brasileira & 1,1 \\
\hline Gender and Diversity in Organizations & 2,7 & & \\
\hline Managerial and Organizational Cognition & 2,6 & & \\
\hline Conflict Management & 2,3 & & \\
\hline Health Care Management & 2,3 & & \\
\hline Management Consulting & 1,8 & & \\
\hline Management Spirituality and Religion & 1,3 & & \\
\hline Organizations and the Natural Environment & 1,3 & & \\
\hline Critical Management Studies & N.D. & & \\
\hline
\end{tabular}

ND - Não disponível 
pelos recantos mais meridionais do continente. Raciocínio semelhante explicaria a maior participação da área equivalente a "Gestão de Ciência e Tecnologia" no encontro do norte. O que parece mais surpreendente, portanto, é a participação, quase três vezes maior, da área de "Administração da Informação" no encontro brasileiro.

A diferença em torno das áreas de "Gestão de Operações e Logística" e "Operations Management" já não é tão grande, podendo, ao menos parcialmente, ser explicada pelo fato de haver mais áreas no encontro da Academy um maior denominador. O mesmo raciocínio parece poder ser empregado para "Teoria das Organizações" e "Organizational and Management Theory".

Por fim, cabe comentar as diferenças, em termos de percentual de submissões das áreas relativas à gestão pública e ao ensino e pesquisa em administração. Enquanto na ANPAD a participação das áreas de "Gestão Pública e Governança" e de "Políticas Públicas" somam $10,7 \%$ do total de submissões, na Academy esse percentual não chega a 1,5\% dos trabalhos submetidos.

Mais uma vez, é provável que a explicação para a enorme discrepância de percentuais provenha dos aspectos culturais predominantes no Brasil e, de outro lado, principalmente nos Estados Unidos, Canadá e Europa. A essas questões somam-se as econômicas, já que é claro o maior peso do setor público em nosso país. Comparando-se as ementas utilizadas por uma e outra associação na descrição dessas áreas, observa-se que aquela utilizada pela Academy é ao menos tão abrangente quanto as utilizadas pela ANPAD, o que reforça a necessidade de uma explicação cultural /econômica.

As áreas relativas a ensino e pesquisa em administração encontram uma posição recíproca às áreas da administração pública, já que na ANPAD há apenas uma área, enquanto na Academy o tema divide-se em dois tracks, um mais voltado à pesquisa e o outro mais ao ensino. Nesse caso, porém, os percentuais (compostos) de submissão são bastante próximos.

$\mathrm{Na}$ próxima seção, discute-se um outro importante parâmetro de comparação entre os eventos: seu custo.

\section{CUSTOS}

A participação na conferência da Academy custou, em 2002, US\$ 265 para inscrição prévia e US\$ 310,00 para inscrição no local. Adicionando-se a esse valor o preço médio das diárias nos hotéis do evento - que, em 2002, foi de aproximadamente US $\$ 150$ (média dos cinco hotéis utilizados pela Academy) -, tem-se um custo total médio de US\$ 715. O último Enanpad, por sua vez, teve uma inscrição equivalente a US\$ 150 (ao câmbio de setembro) e suas diárias chegaram, no caso do hotel mais caro, a aproximadamente US $\$ 100$. Em outras palavras, o evento básico, que tem a duração de três dias - não incluindo o consórcio doutoral e outras atividades préevento de ambas as organizações -, sai, na Academy, a um custo médio total de aproximadamente uma vez e meia o valor do Enanpad, que perfaz, no máximo, US\$ 450. Deve-se observar ainda que, enquanto no evento nacional todas as refeições principais, com exceção de um jantar, estiveram incluídas na estimativa, no caso norte-americano a inscrição cobriu apenas um almoço. Com base nesses dados, pode-se, portanto, afirmar que, desprezando-se as diferenças de custo de transporte, o evento norte-americano custou aproximadamente o dobro de seu equivalente brasileiro ao câmbio de setembro de 2002 (US\$ $1=\mathrm{R} \$ 3$ ).

Observa-se, também nesse aspecto, algumas oportunidades de evolução para o encontro brasileiro. Por exemplo: a conferência do norte tem um orçamento total de quase US\$3,5 milhões, enquanto o encontro brasileiro não chega a $8 \%$ desse montante. Para conviver com custos tão altos, a Academy conta com um elevado número de patrocinadores (15, contra apenas um patrocinador privado no caso brasileiro) e de expositores (quase 60, contra 17 do último Enanpad). Obviamente, essas "oportunidades" envolveriam a busca de mais patrocinadores, além do aumento do número de expositores no evento, visando a uma elevação da arrecadação sem ônus a seus congressistas.

Por outro lado, deve-se observar que somente a contínua elevação do número de participantes nos encontros nacionais poderá torná-los mais atraentes a patrocínios e a exposições de produtos e serviços. Ressalta-se que, em termos de número de participantes, o evento da América do Norte está quase uma ordem de grandeza acima do encontro da ANPAD.

\section{PROCESSOS INTERNOS E SELETIVOS}

Neste tópico, ficam mais equânimes os pontos fortes e fracos de cada um dos eventos. A Academy conta com várias dezenas de organizadores voluntários, enquanto o evento nacional teve como base de sua estrutura interna apenas uma diretoria executiva composta por três pessoas e os 15 coordenadores de áreas.

No que se refere à informatização, o encontro brasileiro tem um sistema totalmente informatizado há al- 
guns anos, enquanto o encontro da Academy veio a atingir $95 \%$ de processamento eletrônico de papers apenas em 2002, sendo que esse percentual foi atingido após um enorme esforço, motivado pelo medo associado aos atentados postais (utilizando a bactéria Antrax) ocorridos nos Estados Unidos naquele ano. Para se ter uma melhor idéia do que isso representa, deve-se observar que, até 2001, o sistema eletrônico não tinha ainda atingido $65 \%$ do processamento de papers na Academy.

Outro importante aspecto tange à questão do processo seletivo. Enquanto o evento nacional adota dez critérios universais na seleção de trabalhos (listados na Tabela 2), a Academy adota critérios que variam um pouco a cada ano e de área para área. A título de exemplo, a Tabela 2 lista também os critérios utilizados na área de "Organizations and Management Theory" da Academy em 2001.

Na referida Tabela, observa-se que o Enanpad utiliza alguns itens a mais que a Academy, embora haja similaridade entre os dois conjuntos de critérios. Por exemplo, o quesito "Technical Adequacy" divide-se em uma questão relativa ao rigor conceitual e outra relativa à adequação da análise realizada. Certamente, papers com boas avaliações nesses quesitos seriam igualmente bem avaliados em termos de "Metodologia Utilizada", "Consistência Teórica do Trabalho" e, provavelmente, "Revisão da Literatura". O quesito "Craftmanship" encontra, também, paralelos em "Clareza, Pertinência e Consecução de Objetivos" e "Qualidade da Redação e Organização do Texto". Outros quesitos, como "Contribuição ao Conhecimento na Área" e "Análise de Dados e Resultados", são praticamente idênticos em ambos os processos.

Ainda com relação à seleção de trabalhos, deve-se destacar o fato de que a Academy contou, em 2002, com quase 3,8 mil avaliadores de todo o mundo (41 países) contra, aproximadamente, 200 no evento brasileiro. Se, por um lado, o trabalho do avaliador da Academy fica facilitado, por outro, o enorme número de avaliadores impede o trabalho estatístico que é realizado no processo seletivo do Enanpad, podendo também levar a uma discrepância muito grande entre os conceitos e as escalas de avaliação utilizadas entre os milhares de referees e sua miríade de culturas. A maior concentração de avaliações, no caso da ANPAD, provavelmente permite uma maior proximidade e uma relativa uniformização das referidas escalas e conceitos envolvidos na avaliação. O outro lado dessa moeda poderia ser uma tendência à endogenia da pesquisa brasileira na área. Esse assunto oxigenação na avaliação de trabalhos - será retomado na conclusão deste texto.

No caso brasileiro, o menor número de avaliadores e o conseqüente maior número de avaliações por avaliador permitem, por meio de um processo estatístico padrão, a minimização do viés das avaliações, já que o que se utiliza para o ranking de trabalhos no processo seletivo dos Enanpads é o número de desvios padrão que cada artigo tem em relação à média de cada avaliador.

\section{FORMATO DAS APRESENTAÇÕES E INTERDISCIPLINARIDADE}

Na questão dos tipos ou formatos de apresentação de trabalhos, o encontro nacional tem mais de $95 \%$ deles apresentados de forma tradicional, ou seja, como seminários de 15 a 20 minutos e audiência disposta em formato de auditório, reservando-se alguns minutos para debates ao final da apresentação ou da sessão de apre-

Tabela 2 - Critérios de análise ANPAD X Academy.

ANPAD
Clareza, pertinência e consecução dos objetivos
Qualidade da revisão de literatura
Consistência teórica do trabalho
Metodologia utilizada
Qualidade da redação e organização do texto
Conclusões: fundamento, coerência e alcance
Análise de dados e resultados: articulação teórica e metodológica
Contribuição do trabalho para o conhecimento na área temática
Originalidade do trabalho
-
Relevância do tema

Technical adequacy

Conceptually rigorous

Appropriate analyses

Craftsmanship

Conceptually rigorous

Appropriate analyses

Contribution to knowledge

Original \& interesting

Conceptually rigorous

Appropriate analyses

Fonte: Elaboração do autor a partir de informações da ANPAD e da Academy of Management 
sentações. Na Academy, esse formato é usado por cerca de $55 \%$ dos trabalhos aceitos, sendo esse percentual complementado por cerca de 30\% de apresentações no formato interactive paper, no qual ocorre uma apresentação simultânea de quatro trabalhos complementares em torno de uma mesa, junto a qual se sentam os autores e um debatedor, e o público acomoda-se em cadeiras dispostas em círculos concêntricos. O restante dos trabalhos da Academy são apresentados em formato symposia (no Enanpad, denominados de "painéis", a partir de 2000, e de mesas-redondas, até então). Além dessas formas, nos dois casos existem as conferências plenárias. No evento nacional, há sempre uma delas em sua abertura e eventualmente outra em seu decorrer ou encerramento. Em 2002, o evento norte-americano contou com 33 dessas conferências plenárias.

Em termos de trabalhos interdisciplinares, há, na Academy, a prática de se trabalhar com $10 \%$ a $15 \%$ de papers inter-áreas. Nesse caso, o coordenador de cada área (ou até mesmo o autor do trabalho) indica uma segunda ou terceira área que será co-responsável pela análise e apresentação do paper. No Enanpad, esse tipo de apresentação, assim como sessões de interactive papers, ainda não foi testado. Esse assunto também será retomado ao final deste texto.

\section{INTERNACIONALIZAÇÃO E DISTRIBUIÇÃO DA PRODUÇÃO}

O encontro da Academy recebeu, em 2002, submissões de mais de 50 países; o da ANPAD, pouco mais de dez. Mas é em termos de parcela de submissões que se pode ter uma real avaliação do grau de internacionalização dos eventos: enquanto no encontro da AOM as submissões estrangeiras atingiram 30\% do total, no XXVI Enanpad esse percentual foi dez vezes menor. É importante observar, também, que na Academy o INSEAD da França e a National University de Singapura ocuparam, respectivamente, o oitavo e o décimo lugar no ranking das instituições com maior número de trabalhos aceitos no evento. No caso do encontro nacional, nenhuma instituição estrangeira situa-se entre os 20 maiores participantes, embora em áreas temáticas específicas isso tenha acontecido. Em 2002, por exemplo, a Universidade de Coimbra teve 5\% dos trabalhos aceitos na área de Estratégia nas Organizações. No total, o evento brasileiro, em 2002, recebeu 3\% de trabalhos estrangeiros, resultando em cerca de $4 \%$ do total de trabalhos aceitos. Essa diferença de percentuais parece mostrar que a par- ticipação estrangeira tende a melhorar a qualidade do evento, já que, com base nessa pequena amostra, percebe-se um melhor desempenho médio dos trabalhos estrangeiros em relação às submissões originadas no país.

$\mathrm{Na}$ Tabela 3, a seguir, apresentam-se os rankings de países em termos de número de trabalhos aceitos nos eventos (excetuando-se os Estados Unidos, no primeiro caso, e o Brasil, no segundo).

Tabela 3 - Ranking de países pelo número de trabalhos aceitos.

\begin{tabular}{|c|c|}
\hline $\begin{array}{c}\text { MEETING OF THE ACADEMY } \\
\text { OF MANAGEMENT }\end{array}$ & $\begin{array}{l}\text { ENCONTRO } \\
\text { DA ANPAD }\end{array}$ \\
\hline Canadá - 178 & Portugal - 13 \\
\hline Reino Unido - 174 & Canadá - 4 \\
\hline Austrália - 104 & Estados Unidos - 3 \\
\hline França - 74 & Reino Unido - 3 \\
\hline Holanda - 70 & França - 2 \\
\hline Singapura - 56 & Espanha - 2 \\
\hline Hong Kong - 39 & Japão - 1 \\
\hline Alemanha - 36 & \\
\hline Israel e Suécia - 34 & \\
\hline Suíça e China - 32 & \\
\hline Espanha - 25 & \\
\hline Bélgica - 22 & \\
\hline Nova Zelândia - 20 & \\
\hline Itália - 18 & \\
\hline Korea - 17 & \\
\hline Noruega - 16 & \\
\hline Dinamarca - 14 & \\
\hline Brasil - 12 & \\
\hline Japão - 11 & \\
\hline Irlanda - 10 & \\
\hline
\end{tabular}

A Tabela 3 mostra uma participação brasileira muito modesta frente a outros países, o que não parece compatível com o volume da produção brasileira - haja vista o número de trabalhos submetidos ao XXVI Enanpad. Um importante questionamento a ser feito, portanto, é o porquê dessa pequena participação.

Aparentemente, há diferentes respostas (complementares) a essa questão. A primeira e mais importante delas é a qualidade da produção científica nacional em administração, tema que será discutido na próxima sessão. Outra razão aparente é de natureza cultural. A maior parte de nossos pesquisadores, considerando a base de mais de 3 mil autores que enviaram trabalhos ao encontro brasileiro, não tem ainda o costume ou mesmo a ambição de publicar internacionalmente. Parece haver quase que uma "timidez coletiva" no que tange a publi- 
car e apresentar trabalhos em fóruns internacionais. Obviamente, as questões financeiras, muito ligadas ao aspecto cambial, são um terceiro impedimento. Em termos institucionais, pode-se dizer que a ANPAD percebe claramente a ameaça que vem a ser essa "inércia nacional" frente à publicação internacional ${ }^{1}$. Essa citada "ameaça" pode ser percebida no claro preenchimento de espaços científicos internacionais destinados aos países em desenvolvimento. Países como a China e alguns dos chamados Tigres Asiáticos têm ocupado espaços de publicação e em projetos internacionais de pesquisa que relegam o Brasil a uma participação que não reflete, absolutamente, os padrões de sua pós-graduação - a qual, em seu conjunto, é, em princípio, uma das mais bemsucedidas entre os países em desenvolvimento. Essa condição é percebida pela atual diretoria da ANPAD como um grande desafio, desafio este que tem reflexos nas estratégias adotadas em seus encontros nacionais, conforme é discutido na última sessão.

Outra questão importante no que tange à distribuição de trabalhos aceitos por instituição de ensino, pode ser percebida ao se observar que os 11 primeiros colocados no ranking da Academy respondem por menos de $12 \%$ do total de trabalhos aceitos, enquanto no Enanpad os 11 primeiros colocados no ranking respondem por $60 \%$ desse total. Obviamente, a diferença deve-se muito mais ao pequeno número de instituições participantes do evento nacional quando comparado ao meeting da AOM. Por outro lado, esse número mostra uma evolução significativa, já que, em 2001, esse percentual passava dos 70\%, ou seja, há um sensível processo de descentralização da produção na área no Brasil.

\section{ESPECULANDO SOBRE A QUALIDADE DOS EVENTOS E DOS TRABALHOS NELES APRESENTADOS}

Em termos de organização, certamente os Enanpads e os meetings da Academy of Management são, ambos, eventos de classe mundial. Os sistemas de submissão, análise de trabalhos, divulgação de resultados, apresentação de trabalhos e secretarias de evento são adequados e funcionam sem grandes surpresas em ambos. Devese destacar que no encontro da Academy não se utiliza o sistema de anais com trabalhos completos em CDROM, mas apenas o abstract dos trabalhos, estando essa opção, aparentemente, relacionada a aspectos de propriedade intelectual daquele país.

Em termos de trabalhos apresentados, simpósios e conferências, há significativas diferenças, uma vez que a Academy é uma referência mundial, na qual se encontram dezenas dos autores mais citados no mundo da gestão. Esses "grandes medalhões" podem ser vistos nas gigantescas conferências plenárias, assim como nos usuais seminários e simpósios e até mesmo nas pequenas sessões de interactive papers. Ao se analisar a grande massa de autores desconhecidos, pode-se perceber alguma polêmica sobre a qualidade dos eventos entre aqueles que freqüentam ambos.

Pode-se especular que, muito provavelmente, a quase totalidade dos trabalhos aceitos na Academy seria também aceita nos encontros da ANPAD. Uma afirmativa simetricamente contrária a essa, entretanto, certamente não pode ser feita com a mesma segurança. Como mencionado anteriormente, é provável que o "trabalho médio" do meeting fosse aceito no Enanpad. Também é provável que algo como o terço ou o quartil superior dos trabalhos aceitos nos últimos Enanpads tivesse um alto índice de aceitação na Academy, a depender da área de submissão. Ainda lembrando que tudo isso não passa de assumida especulação, deve-se ressaltar que, indubitavelmente, a qualidade científica do evento norte-americano é nitidamente superior, particularmente nas questões ligadas à metodologia de pesquisa. Mais uma vez, toca-se em uma questão que envolve os desafios que se colocam à gestão da ANPAD e seu encontro. Alguns desses desafios são discutidos a seguir.

\section{OS DESAFIOS A SEREM ENFRENTADOS}

Mesmo reconhecendo no meeting um evento que é um benchmark internacional, percebem-se alguns desafios ao futuro do mesmo. Os mais simples desses desafios são compostos por aspectos aparentemente triviais, como a manutenção do padrão de qualidade logística do evento e sua total transferência de sistemas para meios eletrônicos. É importante ressaltar que, embora algumas coisas "pareçam" triviais, nada, em realidade, é trivial em um evento científico com mais de cinco mil participantes e 23 áreas de concentração.

Em relação aos maiores desafios, a Academy parece, segundo alguns assíduos freqüentadores, eternamente presa aos dilemas e limitações de uma existência um pouco afastada da vida real das organizações, debatendo-se constantemente frente à sua incapacidade de produzir pesquisas que "façam diferença no mundo real". Nesse aspecto, é interessante observar que, mesmo sendo enorme (12 mil membros), internacional e bem co- 
nhecida pela sociedade como um todo, a Academy só tem $7 \%$ de participantes executivos - os demais são $67 \%$ de professores e $26 \%$ de estudantes. Outro desafio se tornou tão grande que foi escolhido como tema para o meeting de 2003: a democracia interna da organização.

Obviamente, as dificuldades da Academy não são uma peculiaridade dela. Certamente a ANPAD sofre das mesmas dúvidas e questionamentos, embora, neste caso, tais problemas sejam diluídos pela presença imediata de questões mais urgentes e importantes, como, por exemplo, a elevação de seus patamares de qualidade acadêmica e sua internacionalização. Em 2003, a chamada de trabalhos do Enanpad sofreu, após muitos anos, uma mudança no número máximo de páginas a serem aceitas para submissão. A elevação desse padrão para 16 páginas tem o caráter simbólico de ser dedicado a uma melhor descrição da metodologia dos trabalhos e do aperfeiçoamento de suas seções de conclusão. Entendese que a abordagem simplista das questões metodológicas e a generalizada falta de articulação entre as conclusões dos trabalhos e seus arcabouços teóricos são um lugarcomum na produção científica da área no Brasil.

No que tange à organização dos encontros em si, um dos maiores desafios é conseguir absorver o constante crescimento do evento sem perda de sua qualidade, sem uma elevação significativa de custos e sem correr o risco do continuísmo e da rotina. Nesse sentido, o encontro de 2003 trará a realização de sessões interativas. Essas sessões, descritas anteriormente, poderão ocupar até $20 \%$ do total das apresentações em algumas áreas. O percentual citado deve ser visto apenas como um balizador, uma vez que sua concretização depende basicamente das interfaces existentes entre os trabalhos aceitos para as diferentes áreas temáticas. Além das sessões interativas, também os painéis se constituirão em novas formas de apresentação, uma vez que, já em 2003, a constituição dos mesmos será papel basicamente dos coordenadores de áreas temáticas. Essa flexibilização da organização do evento e de suas sessões permitirá, também, uma maior valorização do papel dos coordenadores de área, já que eles passam a ser mais pró-ativos, podendo atuar mais positivamente na definição de tendências e fronteiras em suas respectivas áreas.

$\mathrm{O}$ aspecto da internacionalização, acima mencionado, é visto pela própria Academy, que já tem 30\% de suas submissões de papers geradas no exterior, como um de seus desafios, o que dá uma idéia de sua premência no caso da ANPAD. Assim sendo, a Associação está atuando por diferentes vias, visando à aceleração desse processo. Por um lado, foi realizado um acor- do com a própria Academy, objetivando a divulgação recíproca de seus encontros. Por outro, procurou-se a atração de coordenadores e "co-coordenadores" estrangeiros para três das 17 áreas em que o XXVII Enanpad vai se dividir. A participação de autores estrangeiros nos Enanpads é quase tão pífia quanto a participação de autores brasileiros em eventos internacionais de peso na área de administração. O evento de 2003 da ANPAD traz consigo alguns esforços que visam à aceleração de seu processo de internacionalização. Neste ano, a chamada de trabalhos terá sua difusão internacional incrementada, entre outras formas, por sua distribuição entre os associados da própria Academy. Além disso, as três coordenações internacionais envolvem pesquisadores de renome mundial e de origens tão diversas como a Europa e as Américas do Norte e do Sul. Imagina-se que essas iniciativas poderão mitigar as limitações do incipiente processo de internacionalização até aqui empreendido. As coordenações internacionais deverão trazer consigo a participação de mais autores estrangeiros e até mesmo de avaliadores internacionais, o que certamente contribuirá, em muito, para garantir uma nãoendogenia das práticas de avaliação.

Observa-se que a "multinacionalização" de eventos científicos é uma necessidade generalizada. Os contatos recentemente mantidos entre a ANPAD e a Academy revelaram um enorme interesse desta última em se associar à ANPAD por meio de um acordo de divulgação e representação nos respectivos eventos. Participar dessa "negociação" mostrou que o interesse da Academy no incremento da submissão de papers brasileiros é tão grande quanto sua recíproca.

Por fim, pode-se dizer que os dados aqui apresentados permitem uma comparação direta e simples dos dois encontros, que certamente estão entre os maiores do mundo em termos de eventos científicos na área de administração. Não obstante os números impressionantes dos eventos, não se deve imaginar que os mesmos tenham alcançado seus limites. A Academy recebeu 20\% a mais de papers em 2002, quando comparado ao ano de 2001. No Enanpad, esse crescimento superou os $40 \%$. Os desafios continuam se apresentando a ambas às instituições.

Os dados da Academy certamente servirão como inspiração para algumas inovações no Enanpad, porém, este não deve perder suas características. São justamente tais características que ainda permitem que, mesmo com um total de 850 inscritos, seja mantido, orgulhosamente, um clima tupiniquim de camaradagem e de reencontro. Será possível ou desejável a manutenção desse clima? 
Será esse crescimento compatível com as novas estruturas organizacionais, logísticas e científicas dos encontros da ANPAD? Que papéis caberão aos encontros temáticos como o ENEO - Encontro Nacional de Estudos Organizacionais - e o 3Es - Encontro de Estudos Estratégicos? Outras questões, mais profundas, ficam no ar: pode a ciência apresentada em encontros como o Enanpad e o meeting da Academy of Management "fazer diferença no mundo real"? Que diferenças são desejadas? Quais devem ser seus papéis? Quais são suas contribuições à democracia e à sociedade como um todo?

\section{Artigo convidado. Aprovado em 15/02/03.}

\section{Nota}

${ }^{1} \mathrm{O}$ mesmo pode ser dito em relação à CAPES, que estimula fortemente a publicação internacional por meio do sistema de pontuação adotado no Quallis.

\section{Referências bibliográficas}

BEATTY, J. E. Me, Jack and "The Head" - Collaborative frames at the Academy of Management. Journal of Management Inquiry, Thousand Oaks, v. 11, n. 3, p. 305-15, 2002.

BERTERO, C. O., CALDAS, M. P. e WOOD JR., T. Produção científica em administração de empresas: provocações, insinuações e contribuições para um debate local. In: ENCONTRO ANUAL DA ASSOCIAÇÃO NACIONAL DOS PROGRAMAS DE PÓS-GRADUAÇÃO EM ADMINISTRAÇÃO, $22^{\circ}, 1998$, Foz do Iguaçu. Anais.... 1 CD-ROM.
CALDAS, M. P., TONNELLI, M. J. e LACOMBE, B. M. B. Espelho, espelho meu: um metaestudo da produção científica em Recursos Humanos nos Enanpads da década de 90. In: ENCONTRO ANUAL DA ASSOCIAÇÃO NACIONAL DOS PROGRAMAS DE PÓS-GRADUAÇÃO EM ADMINISTRAÇÃO, 26 $6^{\circ}$ 2001, Salvador. Anais... 1 CD-ROM.

HOPPEN et al. Sistemas de informação no Brasil: uma análise dos artigos científicos dos anos 90. In: ENCONTRO ANUAL DA ASSOCIAÇÃO NACIONAL DOS PROGRAMAS DE PÓS-GRADUAÇÃO EM ADMINISTRAÇÃO, 22º 1998, Foz do Iguaçu. Anais.... I CD-ROM.

MACHADO-DA-SILVA, C., CARNEIRO DA CUNHA, V. e AMBON N. Organizações: o estado da arte da produção acadêmica no Brasil. In: ENCONTRO ANUAL DA ASSOCIAÇÃO NACIONAL DOS PROGRAMAS DE PÓS-GRADUAÇÃO EM ADMINISTRAÇÃO, 14², 1990, Belo Horizonte. Anais.... Belo Horizonte: ANPAD, 1990. Vol. 6 (Organizações), p. 11-28.

PAYNE, R. Annual meeting of the Academy of Management, New Orleans, August $9^{\text {th }}-12^{\text {th }}, 1987$. R\&D Management, Oxford, v. 18, n. 3, p. 279-80, July 1988.

RODRIGUES FILHO, J. Estudos críticos em administração no Brasil Classificação da produção do conhecimento sob a ótica da teoria crítica de Jürgen Hebermas. 2002. Tese (Concurso para Professor Titular) - Universidade Federal da Paraíba, João Pessoa.

TEIXEIRA JR, F. Análise dos métodos de pesquisa utilizados em artigos de administração da informação: levantamento dos artigos publicados nos Enanpads de 1999 a 2002. In: ENCONTRO ANUAL DA ASSOCIAÇÃO NACIONAL DOS PROGRAMAS DE PÓS-GRADUAÇÃO EM ADMINISTRAÇÃO, 26\% 2002, Salvador. Anais.... 1 CD-ROM.

VERGARA, S. e SOUZA CARVALHO JR., D. Nacionalidade dos autores referenciados na literatura brasileira sobre organizações. In: ENCONTRO ANUAL DA ASSOCIAÇÃO NACIONAL DOS PROGRAMAS DE PÓSGRADUAÇÃO EM ADMINISTRAÇÃO, 19², 1995, João Pessoa. Anais.... 1 CD-ROM.

\section{Rogério Hermida Quintela \\ Professor Titular da Escola de Administração da UFBA, Diretor Científico da ANPAD. \\ Ph.D. em Administração Estratégica pela University of Brighton - UK. \\ E-mail: secretaria@anpad.org.br \\ Endereço: Escola de Administração da UFBA, Av. Reitor Miguel Calmon S/N, Vale do Canela, CEP 40110-100, Salvador, BA.}

